61st IFLA General Conference - Conference Proceedings - August 20-25, 1995

\title{
SCHOLARLY COMMUNICATION AND THE USE OF NETWORKED INFORMATION SOURCES
}

\author{
Yaşar Tonta \\ Hacettepe University \\ Department of Library Science \\ 06532 Beytepe, Ankara, Turkey \\ Email: tonta@eti.cc.hun.edu.tr
}

\begin{abstract}
This paper examines the use of networked information sources in scholarly communication. Such use is reflected, among others, in the footnotes and bibliographies of scholarly articles published in print journals. Twenty-seven print journals representing a wide range of subjects were identified through the ISI's SCI and SSCI Journal Citation Reports. Journals that were selected were those that published the most influential papers in their respective fields during the period of 1990-1993, and thus consistently ranked at the top in terms of their impact factors. From these top journals, a total of 97 articles were selected for further review. Footnotes and bibliographies of those 97 articles were checked to determine if they contained references to networked information sources such as electronic journals and archives accessible through the network. Only two (out of 97) articles contained such references. Findings were discussed in light of other studies published in the relevant literature. Some explanations were also offered as to why references to networked information sources appear relatively infrequently in scholarly articles published in print journals.
\end{abstract}

\section{PAPER}

\section{INTRODUCTION}

The history of the use of electronic mail by the academic community goes back to the early 1970s. Parallel publication of both the electronic and print versions of the same journals has started with the American Chemical Society (ACS) in 1983 when it offered the full-text of its journals through BRS, a commercial online information services company. Yet, publishing via the Internet and related academic networks "took off" in 
1990 after the "cold fusion" controversy of 1989 (Schauder, 1994: 77-78). The use of networks as a medium of publication has proliferated since then. The fifth edition of the Directory of Electronic Journals, Newsletters and Academic Discussion Lists, compiled by a team headed by Diane Kovacs and published by the Association of Research Libraries, contains entries for "nearly 2500 scholarly lists and 675 electronic journals, newsletters, and related titles such as newsletter-digests --an increase in size of over $40 \%$ since the 4th edition of April 1994 and 4.5 times since the 1st edition of July 1991" (Okerson, 1995).

Although the number of electronic journals and newsletters available through the network increased tremendously over the last couple of years, the use of networks as a means of publishing scholarly articles has not been accepted readily by the academic community. Schauder (1994) conducted a survey in the second half of 1992 and found that scientists used networks mainly for electronic mail. Yet, only a small proportion (7\%) of scholars used networks to obtain information or publish articles therein (p.89) and the majority of them would prefer to read the printed copies of articles (p.91). Most scholars tend to be skeptic about the virtues of electronic publishing as the medium is "still widely perceived as unfit for serious scholarship, more like a global graffiti bound for trivial pursuit" (Harnad, 1993). Stoller (1992) shares similar views in his comparison of electronic journals and print journals:

The electronic journal is a hybrid. It springs from an effort to merge the informality, speed, and relative cheapness of network communication with the durable scholarship of the print world. In some degree, it is a hopeless endeavor, because the two components are so very different and indeed contradictory. How does one inject durability into an electronic medium that is by nature transient or bring speed and cheapness to a print format that has become incurably cumbersome and expensive?...But, if the electronic journals fail to achieve some form of formality of their print cousins, they will also fail to make a lasting contribution to scholarship (p.666).

Schaffner (1994) reaches similar conclusions and points out that in order for electronic journals to be accepted as the medium of choice for publishing articles they must "meet the basic needs that print journals do, that they will initially maintain many of the features of traditional print journals, that their transformation may be driven by external forces, and that they will be slow in reaching their full potential" (p.239).

Lynch (1993a) observes that network-based electronic scholarly communication is currently supported by a few professional societies such as ACS and the American Mathematical Society (AMS) and some other "difficult-to-characterize" organizations such as OCLC and the presence of the traditional print publishers is yet to be felt in the field of scholarly electronic communication as they commit few resources (p.19). One of the reasons is economics. The new system of scholarly communication offers a plethora of economic models ranging from charging by item or subscription or combination of both to individual or institutional licenses to encrypted keys. Traditional print publishers 
are probably not going to be overly enthusiastic about electronic scholarly communication unless the economics of the system is resolved to their satisfaction. Even though, as Singleton (1993) indicates, the traditional print publishers receive most of their journal material in electronic form from authors, they will not migrate their publications to the electronic form unless they are certain that they can get "an extended, or perhaps indefinite, period of parallel publishing" rights (p.31).

Singleton (1993) also points out that as long as "...the marginal cost of producing and distributing paper copies remains a small proportion of the total cost, relatively few cost savings can be expected from such systems" (p.31). This explains to some extent why print publishers are reluctant to switch from print to electronic form. It also explains why they currently tend to see parallel publishing simply as an alternative distribution medium to reach a wider audience and they will continue to offer the electronic alternative as long as they continue to earn at least the same amount of money from the hard-copy subscriptions. It appears then that print publishers are not going to change their practices easily unless they know that they can get a good value on their investments.

Financial hazards of moving from a subscription base to a somewhat different economic model is not the only obstacle before the full implementation of network-based scholarly electronic communication. In addition to economic and motivational factors (e.g., lack of incentives), technology plays and important (and, currently, somewhat inhibiting) role in the development of electronic journals. Telecommunication networks of today are simply inadequate to transmit a large amount of non-textual information. For instance, it may take several minutes to transmit a single color picture when the network is busy. Yet multimedia information in the form of graphics, pictures, sound and video can be extremely important for research in some fields (e.g., scientific visualization). It is highly unlikely that network-based scholarly electronic communication lacking such visual information can easily be selected as the medium of choice by most academics publishing in those fields. Moreover, it is almost impossible to transmit high quality video through the current networks as it demands a large amount of bandwidth, not to mention interactivity. As King (1991) points out:

...research papers will have motion simulations or video, with sound. We are going to see the reverse of what we have now. Presently the online version of a journal refers to the print version for the figures and illustrations. Seven to ten years from now, it will be the print version which refers to the electronic one for moving illustrations and sound. At that point the electronic version will be the definitive one --the one that must be archived (p.10).

Stoller's comments show to some extent that, despite the proliferation of well-designed user interfaces to networked information sources, printed copies continue to be preferred by scholars in some disciplines as print journals have the easiest user interface. Stoller also predicts that "...the individual subscription structure that has predominated on the networks to date simply will not allow electronic journals to take a central place in the world of scholarly communication" as "...most scholars actually subscribe to and 
routinely examine just a handful of journals, making only occasional use of others" (p.658).

Singleton (1993) points out that the route to fully electronic scientific communication is littered with pitfalls such as incomplete networks, questions of control, copyright, and unfixed price issues (p.27). Lynch (1993a) foresees that:

...some of these network-based electronic communication processes will survive and grow, at least as a supplement to the existing print-based system. We do not yet understand fully what the transfigured system of scholarly communication will be. It is virtually certain, however, that some elements of the existing print publishing processes (perhaps much changed) will be brought forward, but it is not essential that publishing, as we view it, be fully and faithfully transported into the electronic environment (p.6-7).

So far we have briefly summarized the development of network-based scholarly electronic communication and discussed some of the problems that need to be resolved. Despite the fact that there are many issues to be addressed in this area, it is encouraging to see a large number of electronic journals that are actually run by the academics. They range from "barely moderated bulletin boards to fully refereed electronic journals" (Singleton, 1993: 28). Among the refereed journals are Online Journal of Current Clinical Trials, Electronic Journal of Communication, The Public-Access Computer Systems Review, EJournal, Postmodern Culture, Journal of Fluids Engineering, Journal of Geography and Mathematics, Nuclear Physics Reports, and Psycoloquy. Some of these journals are offered free of charge while others can be obtained via subscription.

In addition to the ones cited in this paper, several articles and bibliographies, published in electronic as well as in print journals, can be found in the literature on scholarly electronic communication through the networks (e.g., Bailey, 1995; Graham, 1994; Cohen, 1993; Michelson \& Rothenberg, 1992; Kahin, 1992; Rawlins, 1992; PACS Review, 1991; Bailey \& Rooks, 1991). There also is a discussion list on electronic journals (HYPERJOURNAL@MAILBASE.AC.UK). Yet, research on networked information sources and their use in scholarly communication is scarce. In this paper, we examine the impact of networked information sources on scholarly communication by means of citation data available through the footnotes and bibliographies of articles published in print journals.

\section{SCHOLARLY COMMUNICATION AND THE USE OF NETWORKED INFORMATION SOURCES}

Schauder (1994) defines "electronic publishing" as the "[d]issemination and archiving of full-text professional articles via computer storage media (e.g., magnetic or optical disks). Access is through computers in stand alone mode and/or connected to communication networks" (p.74). Schauder's definition can to some extent be used for "networked information" as well since "networked information" is also disseminated, archived and 
accessed in the same manner. Lynch (1993b) enumerates "networked information sources":

...documents -text, images, or compound multimedia objects- stored on network hosts, as well as data files, databases, objects stored in databases, interactive services, newsgroups, LISTSERV lists, interactive information retrieval services, electronic sensor feeds, and, hopefully, new electronic information resources and formats yet to be developed (p.3)

\section{Method}

In January 1995, a survey was conducted in order to find out how heavily, if at all, networked information sources are cited in scholarly print journals published in 1993 and 1994. First, printed journals that publish the most influential papers, and thus consistently rank at the top in terms of their impact factors, were identified through the Science Citation Index and Social Science Citation Index Journal Citation Reports (1990-1993), regularly published by the Institute for Scientific Information (ISI). A total of 27 print journals representing a wide range of subjects (Chemistry, Engineering, Sociology, Social Science, Library \& Information Science, and Business) were selected. The following journals ranked at the top in their respective fields during the period of 19901993:

- Gen. Chemistry: Accounts of Chemical Research, Chemical Reviews, Angewandte Chemie, J. of the Amer. Chem. Soc.

- Engineering: Combustion and Flame, Combustion Science \& Technology, International J. for Numerical Methods in Engineering, International J. of Engineering Science

- Sociology: Amer. Sociological Rev., J. of Marriage \& Family, Amer. J. of Sociology, Sociology, Ethology and Sociobiology

- Soc. Science: Research in Organizational Behavior, J. of Sex Research, Daedalus, J. of Conflict Resolution, Social Science Research

- Lib. \& Info. Sci: J. of Amer. Soc. for Info. Science, Annual Rev. of Info. Science \& Technology, College \& Research Libraries, J. of Documentation, Library Resources \& Technical Services

- Business: J. of Consumer Research, Academy of Management J., Administrative Science Quarterly, Harvard Business Review

Since the present study aims to find out the state of the art of the use of networked information sources in scholarly communication, we examined only the last two volumes (1993 and 1994) of each journal. Two articles for each volume were chosen. In other words, a total of four articles representing each journal were selected. One of the articles came from the first issue and the other one from the last issue of each volume. The very first article in each issue was chosen for further examination. Items such as editorials, prefaces, presidential addresses, etc. were not taken into account. A total of 97 articles were examined in order to determine if their bibliographies included references to networked information sources. 
Footnotes, notes and the bibliography of each article selected for further examination were checked to determine if they contained references to networked information sources such as electronic journals, electronic mail and ftp archives, messages to electronic discussion lists, personal communication and unpublished manuscripts.

\section{Findings}

Table 1 provides statistical data on our findings (table unavailable; please contact author to obtain the table). As the table shows, out of a total of 97 articles, only two contained direct references to networked information sources. One of those articles, published in the Journal of the American Society for Information Science in 1994, was on publishing and the author reviewed the current developments in publishing and cited the Public-Access Computer Systems Review, a refereed electronic journal. The print versions of some other electronic journals such as Wired, Online Journal of Current Clinical Trials, and Internet Society News were also mentioned in that article. The second article, published in Daedalus in 1993, contained a direct reference to an electronic mail message sent to a discussion list.

Apart from the two references to networked information sources mentioned above, we identified seven references to private communications, 13 references to unpublished manuscripts, two references to lab results, and one reference to a working paper.

However, it was not clear if the private communications were in the form electronic mail messages. Similarly, we do not know if any of those unpublished manuscripts, lab results, or the working paper was available to others by means of electronic communication networks and the data we gathered in our survey does not lend itself to further statistical tests (e.g., do citation types and patterns differ in science and social science journals?).

What has clearly emerged out of our survey is that networked information sources received a very few citations in the top-ranked print journals during the period of 19931994.

\section{Discussion}

Although findings of this study are based on the last two years' (1993-1994) citation data of networked information sources and the results cannot be generalized to the overall scholarly electronic communication activities, it is no exaggeration to suggest that networked information sources in the form of electronic journals and archives get almost no citations in print journals at all. This is a most surprising finding of the present study as we expected, at the beginning of our research, to find more citations to networked information sources that are available through the network by means of electronic mail, ftp, gopher and WWW protocols.

Although methods used in two studies differ, our findings, to some extent, corroborate that of Schauder (1994). He used a questionnaire survey to obtain detailed data on the perceptions of scholars using electronic mail as well as using the network as a medium of publication and information distribution and retrieval tool. We on the other hand looked 
at if scholars make use of networked information sources in their research and see if this is reflected through the footnotes and bibliographies of articles that they publish in print journals. In other words, the present study would to a certain extent show the difference between what scholars say they do and what they actually do.

As we pointed out earlier, Schauder (1994) found that scholars used the network mostly for sending and receiving electronic mail and that only a small proportion of them (7\%) said they used the network to obtain information or publish articles therein. We found that only two out of 97 articles (2\%) did actually contain references to networked information sources. However, this does not necessarily mean that scholars use the network much less frequently. It just means that citing networked information sources in printed articles is but one way of scholar's using the network.

Just as our findings surprised us, such low use of the network surprised Schauder, too. At the beginning of his research, Schauder thought of electronic publishing "as a unicorn, from writing to end-use of articles proceeded in a `paperless manner."' Yet what he found and examined was a "strong, healthy rhinoceros" in the form of print publishing. His main conclusion of his research was that "publication via printed journals is extremely electronically assisted" (Schauder, 1994: 94).

There may be several reasons as to why networked information sources are cited relatively infrequently in print journals. Some of them (e.g., economic and technological issues, motivational factors such as lack of incentives) have already been mentioned at the beginning of this paper. As we have seen earlier, electronic publishing is still in its infancy. Lasting contributions to the scientific inquiry through the articles published in electronic journals have yet to be made. Hence, in the foreseeable future, scholars ought to rely, for their research, on articles primarily published in print journals.

Another reason for why references to electronic journals and other networked information sources in print journals are scarce may be that articles published in electronic journals are not adequately indexed and abstracted in standard reference tools. Smith (1995) checked the titles in Ulrich's International Periodicals Directory (January 1995) and found that only one electronic journal (Online Journal of Current Clinical Trials) had its indexing information listed in Ulrich's. Similarly, articles published in electronic journals have yet to be indexed and abstracted by most A\&I publishers. Smith (1995) lists some of the electronic journals that are covered by major A\&I sources such as Index Medicus, Mathematical Reviews, MLA Bibliography, and Current Index to Journals in Education. However, Woodward (1995) raises the issue of the format of indexing electronic journals and points out that most of the entries are very poor and lack even basic information such as URLs (Universal Resource Locators).

As we have pointed out earlier, scholars seem to be reluctant to publish in the network environment as they see the medium "unfit for serious scholarship." They need assurance that their scholarship will be preserved for future generations without intrusion, distortion or destruction, and that it will be easily accessible (Graham, 1994). In addition, they need 
assurance that articles they publish in electronic journals would get the same recognition as that in print journals during tenure decisions.

In conclusion, it appears that although networked information sources facilitate scholars' work to a great extent during the research process, they have yet to incorporate such sources in the bibliographies of their published articles. It is highly likely that this would continue until the critical mass of lasting contributions to science are published in electronic form and can be obtained through the network. In order for this to happen, technological and economic issues with regards to electronic publishing and networking need to be addressed. The integrity and authenticity of the preserved copy must be assured. Scientists should be supported in their endeavors of scholarly electronic communication through the network. Such initiatives should be encouraged by the universities and other research institutions by equipping academics with the needed knowledge and tools and by recognizing such electronic publishing efforts as scholarly activities.

\section{BIBLIOGRAPHY}

BAILEY, C.W., JR. (1995). "Electronic Publishing on Networks: A Selective Bibliography of Recent Works," (data file updated regularly and sent to the PublicAccess Computer Systems Forum, PACS-L@UHUPVM1.UH.EDU).

BAILEY, C.W., JR. \& D. Rooks, eds. (1991) "Symposium on the Role of NetworkBased Electronic Resources in Scholarly Communication and Research," Public-Access Computer Systems Review 2(2): 4-60. (To retrieve this article in electronic form, send an email message that says "GET BAILEY1 PRV2N2 F=MAIL" to LISTSERV@UHUPVM1.UH.EDU.)

COHEN, J.A. (1993 January). "Electronic Library in Higher Education: An Overview and Status Report," Interpersonal Computing and Technology: An Electronic Journal for the 21st Century 1(1). (article is filed under the name COHEN@IPCTV1N1 and is available from LISTSERV@GUVM.GEORGETOWN.EDU)

GRAHAM, P.S. (1994). "Intellectual Preservation: Electronic Preservation of the Third Kind," The LIBER Quarterly 4: 163-174.

HARNAD, S. (1993). "Implementing Peer Review on the Net: Scientific Quality Control in Scholarly Electronic Journals," (paper presented at the International Conference on Refereed Electronic Journals in 1993; available via ftp from the following address: ftp://electra.cc.umanitoba.ca/e-journal/ICREJ93/).

KAHIN, B. (1992). "Scholarly Communication in the Network Environment: Issues of Principle, Policy and Practice," Electronic Library, 10(5): 275-286.

KING, T.B. (1991). "The Impact of Electronic and Networking Technologies on the Delivery of Scholarly Information," Serials Librarian 21: 5-13. 
LYNCH, C.A. (1993a). "The Transformation of Scholarly Communication and the Role of the Library in the Age of Networked Information," Serials Librarian 23(3/4): 5-20.

LYNCH, C.A. (1993b). "A Framework for Identifying, Locating, and Describing Networked Information Resources," (preliminary draft). January 21.

MICHELSON, A. \& J. Rothenberg. (1992)."Scholarly Communication and Information Technology," American Archivist 55: 236-315.

OKERSON, A. (1995 May 18). "New Edition of Internet Journal Directory Available," email message posted to the Public-Access Computer Systems Forum, PACS-

L@UHUPVM1.UH.EDU.

PUBLIC-ACCESS COMPUTER SYSTEMS REVIEW. (1991). Vol. 2, \#1 is a special issue on electronic journals.

RAWLINS, G.J.E. (1993). "The New Publishing: Technology's Impact on the Publishing Industry Over the Next Decade," in: C.W. Bailey, Jr. et al., eds. The Public-Access Computer Systems Review Volume 3, 1992. (164-219), Chicago: ALA.

SCHAFFNER, A.C. (1994). "The Future of Scientific Journals: Lessons from the Past," Information Technology and Libraries 13(4): 239-247.

SCHAUDER, D. (1994). "Electronic Publishing of Professional Articles: Attitudes of Academics and Implications for the Scholarly Communication Industry," J. of American Society for Information Science 45(2): 73-100.

SINGLETON, A. (1993 November). "Electronic Journals for Everyone," Physics World 6(11): 27-31.

SMITH, A. (1995 January 30). "Electronic Journals in Indexing Services," E-mail message to PACS-L.

STOLLER, M.E. (1992). "Electronic Journals in the Humanities: A Survey and Critique," Library Trends 40(4): 647-666.

WOODWARD, H. (1995). "Electronic Journals: Issues of Access and Bibliographic Control," to appear in Serials Review, 1995 (as cited in Smith (1995) above). 